\title{
ELECO-2007 Conference
}

\author{
Hakan Kuntman · Oguzhan Cicekoglu
}

Published online: 26 April 2009

(C) Springer Science+Business Media, LLC 2009

Welcome to the special Issue on Selected Papers from the ELECO-2007 Conference! This conference is the 5th International Conference on Electrical and Electronics Engineering held on 5-9 December, 2007, in Bursa-Turkey. The history of ELECO conferences goes back to the year 1986, initially organized by the Chamber of Electrical Engineering (EMO)-Turkey Bursa Section as a national conference, under the name ELMEKSEM Electromechanical Conference and was repeated in 1988, 1993, and 1997, respectively.

The EMO Bursa section has yet proceeded to organize another series of national conferences under the name Computer-Telecommunications Conferences. The 5th conference of this series was held in 1998. Until 1999 the conference series remained local, but in 1999 both conferences were united under ELECO and organized as an international Conference. ELECO-1999 was thus the first International Electrical and Electronics Engineering Conference held in Bursa.

It was decided that the conferences be held at an international level in odd numbered years and as a national conference in even numbered years.

With respect to the scope of the technical program, it was probably the largest electrical and electronics

\footnotetext{
H. Kuntman

Faculty of Electrical and Electronic Engineering, Istanbul

Technical University, Maslak, 34469 Istanbul, Turkey

e-mail: kuntman@itu.edu.tr

URL: http://www2.itu.edu.tr/ kuntman/

O. Cicekoglu $(\square)$

Electrical and Electronic Engineering Department, Bogazici

University, Bebek, 34342 Istanbul, Turkey

e-mail: cicekogl@boun.edu.tr

URL: www.ee.boun.edu.tr/cicekoglu.html
}

engineering conference ever held in Turkey. The conference's broad-ranged topics covered electric power systems, electrical machines and drives, power electronics, high voltage techniques, electrical materials, electronics, circuits and systems, signal processing, electromagnetics, antennas and propagation, microwave theory, communication systems, mechatronics, control theory, control applications, automation systems, robotics and intelligent control systems.

From the 268 papers submitted to ELECO-2007, 180 papers were accepted for presentation in the conference. Each paper was carefully reviewed by the international referees. Contributions to ELECO-2007 came from 29 different countries over four continents.

Bursa used to be an important city both in West Roman Empire period and in the Ottoman Empire Period and is still one of the most significant cities of the Turkish Republic. ELECO conferences are becoming traditional biennial events in this historical town of Bursa.

Selected papers from international ELECO Conferences were invited to be published in extended form in special ELECO issues of international journals, under peer review.

This Special Issue consists of eight papers selected from the Electronics Section of the Conference ELECO'2007 under peer review process.

The first paper is entitled: "Low-Noise Amplifiers in Wireless Communications: state of the art, two new wideband all-active LNAs in SiGe-BiCMOS". The aim of this paper is three-fold. First, it introduces the low-noise amplifier, its relevance in modern wireless communications receivers and the performance expected of it. Then, it presents an exhaustive review of the existing topologies, presenting their advantages and shortcomings. Finally, it introduces a new class of LNAs, based on current conveyors, describing the founding principle and the 
performances of two new LNAs, one single-ended and the other differential.

The second paper is entitled "Very high-speed and highaccuracy current-steering CMOS D/A converter using a novel 3-D decoder". In this paper a 10-bit 1.2 GSample/s Nyquist current-steering CMOS digital-to-analog converter (DAC) is presented. Higher performance is achieved using a novel 3-D thermometer decoding method which reduces the area, power consumption and the number of control signals of the digital section.

The third paper is entitled "Trade-offs in the OTA-based analog filter design". In this paper, some trade-offs in the electronically tunable filters are investigated. In addition, the tunability ranges of some first and second order OTA-C and OTA-RC filters are comparatively examined. Moreover, a new OTA-C all-pass filter circuit is presented.

The fourth paper is entitled "A new negative resistance circuit and an application for loss compensation in a distributed amplifier ". This paper presents a new negative resistance (NR) circuit which is designed especially to compensate the losses inherent in conventional distributed amplifiers (CDA).

The fifth paper is entitled "A new 5th-order differential type class-AB log domain elliptic low pass filter for video frequency applications". This paper proposes a new current-mode 5th-order differential type class-AB log domain elliptic low pass filter for video frequency applications. The design is based on the state-space synthesis method.

The sixth paper is entitled "Simulation of a novel current-mode universal filter using FDCCIIs". In this paper, a new current-mode universal active-RC filter is proposed. The proposed circuit is based on a new universal passive filter topology. This passive filter is generated from a classical well known current-mode universal passive filter applying a transformation procedure.

The seventh paper is entitled "Novel high-precision current-mode multiplier/divider". In this paper, a method to reduce the second order effects on the circuit performances caused by the small sized MOS transistors is proposed. A current mode square-root circuit, a squarer/ divider circuit and a multiplier/divider circuit are designed using this method.

The last paper is entitled "The Fractional Frequency Synthesizer with Coincidence Mixer". In this paper, a fractional frequency synthesizer architecture is proposed, employing a new mixer based on signal coincidence, which achieves fast-settling, and high resolution compared with the direct frequency synthesizer based on diophatine equations.

The guest editors would like to thank the Editor inChief, Prof. Mohammed Ismail for his valuable support, Chloe Sandoval for the development of this Special Issue Sonia Barbosa and staff at Springer for their assistance in producing this volume.
We hope you enjoy reading this special issue of Analog Integrated Circuits and Signal Processing.

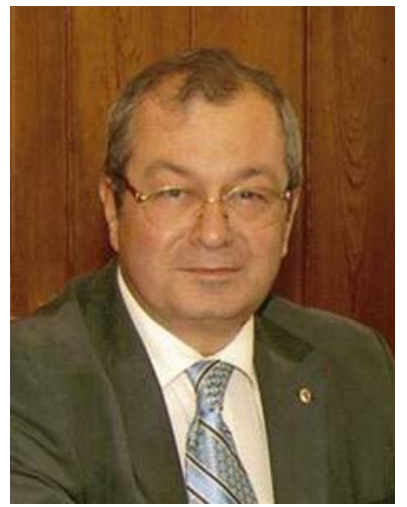

Hakan Kuntman received his B.Sc., M.Sc., and Ph.D. degrees from Istanbul Technical University in 1974, 1977, and 1982, respectively. In 1974 he joined the Electronics and Communication Engineering Department of Istanbul Technical University. Since 1993 he is professor of electronics in the same department. His research interest include design of electronic circuits, modeling of electron devices and electronic systems, active filters, design of analog IC topologies. Dr. Kuntman has authored many publications on modeling and simulation of electron devices and electronic circuits for computer-aided design, analog VLSI design and active circuit design. He is the author or the coauthor of 92 journal papers published or accepted for publishing in international journals reviewed by SCI and EI, 14 journal papers published in other journals, 137 conference papers presented or accepted for presentation in international conferences, 136 Turkish conference papers presented in national conferences and ten books related to the above mentioned areas. Furthermore he advised and completed the work of nine Ph.D students and 38 M.Sc. students. Currently, he acts as the advisor of five $\mathrm{Ph}$.D. students. Dr. Kuntman is a member of the Chamber of Turkish Electrical Engineers (EMO). Currently, he serves as the Dean of Electrical and Electronics Engineering Faculty, Istanbul Technical University, Turkey.

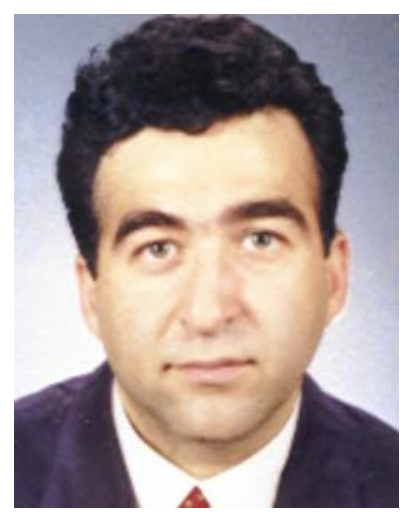

Oguzhan Cicekoglu received the B.Sc. and M.Sc. degrees from Bogazici University and the $\mathrm{PhD}$. degree from Istanbul Technical University all in Electrical and Electronics Engineering in 1985, 1988, and 1996, respectively. He served as lecturer at the School of Advanced Vocational Studies Electronics Prog. of Bogazici University where he held various administrative positions between 1993 and 1999. He has also given lectures at the Turkish Air Force Academy. He was with the Biomedical Engineering Institute of the Bogazici University between 1999 and 2001. Then he joined the Electrical and Electronics Engineering Department of the same University where he became a professor. Since September 2007 he serves as the Dean of Engineering at Corlu Engineering Faculty of Namik Kemal University, Turkey. Oguzhan Cicekoglu served in organizing and technical committees of many national and international conferences. He was the Guest co-editor of a previous Special Issue of the Analog Integrated Circuits and Signal Processing Journal. One of the publications he co-authored in IEEE Transactions on Circuits and Sytems II-Analog and Digital Signal Processing is among the top cited papers listed in IEEE Circuits and Systems Society web page. He received the Research Excellence Award of Bogazici University Foundation in 2004. He served as the co-chair of 
Amplifiers and Comparators track in 50th IEEE Midwest-Newcas Joint Conference which is held in Montreal-Canada and serves as a track chair in the 52th IEEE Midwest Symposium which will be held in Cancun-Mexico in 2009. His current research interests include analog circuits, active filters, analog signal processing applications and current-mode circuits. He is the author or co-author of about 150 papers published in scientific journals or conference proceedings and conducts review in numerous journals including Analog Integrated Circuits and Signal Processing, IEEE CAS-I, IEEE CAS-II, International Journal of Electronics, International Journal of Circuit Theory and Applications, IEE Proceedings Pt.G, ETRI Journal and several others. Oguzhan Cicekoglu is a member of the IEEE and is currently the Associate Editor of International Journal of Electronics. 